\title{
Spontaneously Fermented Fruiting Bodies of Agaricus bisporus as a Valuable Source of New Isolates of Lactic Acid Bacteria with Functional Potential
}

\author{
Katarzyna Skrzypczak ${ }^{1, *}{ }^{\circledR}$, Klaudia Gustaw ${ }^{2}$, Ewa Jabłońska-Ryś ${ }^{1}$, Aneta Sławińska ${ }^{1}$, \\ Waldemar Gustaw ${ }^{1}$ and Stanisław Winiarczyk ${ }^{3}$ \\ 1 Department of Plant Food Technology and Gastronomy, Faculty of Food Science and Biotechnology, \\ University of Life Sciences in Lublin, 8 Skromna Street, 20-704 Lublin, Poland; \\ ewa.jablonska-rys@up.lublin.pl (E.J.-R.); aneta.slawinska@up.lublin.pl (A.S.); \\ waldemar.gustaw@up.lublin.pl (W.G.) \\ 2 Department of Biotechnology, Microbiology and Human Nutrition, Faculty of Food Science and \\ Biotechnology, University of Life Sciences in Lublin, 8 Skromna Street, 20-704 Lublin, Poland; \\ klaudia.gustaw@up.lublin.pl \\ 3 Department of Epizootiology and Clinic of Infectious Diseases, University of Life Sciences in Lublin, \\ Głęboka 30, 20-612 Lublin, Poland; genp53@interia.pl \\ * Correspondence: katarzyna.skrzypczak@up.lublin.pl; Tel.: +48-81-462-33-08
}

Received: 18 October 2020; Accepted: 6 November 2020; Published: 8 November 2020 updates

\begin{abstract}
The aim of the investigation was the identification and initial study of lactic acid bacteria (LAB) isolated from spontaneously fermented (at $28^{\circ} \mathrm{C}$ for 5 days) fruiting bodies of white button mushrooms (Agaricus bisporus). The isolated LAB were preliminarily characterized applying the MALDI-TOF Biotyper. Moreover, further phenotypical, genotypical characteristics as well as some functional and technological properties of the selected microorganisms (including the ability to produce exopolysaccharides, cell hydrophobicity, resistance to low $\mathrm{pH}$, and bile salt) were also analyzed. Among autochthonous LAB (isolated from the tested mushroom raw material), Leuconostoc mesenteroides predominated in spontaneously fermented A. bisporus, while Lactiplantibacillus paraplantarum, Lactiplantibacillus plantarum, and Lactococcus lactis were less abundant. The highest dynamics of acidification of the mushroom material were exhibited by isolates EK55 and EK4 that, after $24 \mathrm{~h}$ of incubation, were able to decrease the $\mathrm{pH}$ of the raw material up to $5.06 \pm 0.021$ and $5.17 \pm 0.015$, respectively. Furthermore, the analysis of bacterial cell hydrophobicity indicated that the highest values of this parameter were noted for L. plantarum isolates EK12 (29.59 $\pm 0.7 \%)$, EK55 $(28.75 \pm 0.551 \%)$, and EK5 $(27.33 \pm 1.516 \%)$. It was revealed some of the analyzed LAB (especially isolates L. plantarum EK55 and L. paraplantarum EK4) exhibited functional and technological potential that might be used in the formulation of novel starter cultures.
\end{abstract}

Keywords: fermentation; Agaricus bisporus; lactic acid bacteria (LAB); MALDI-TOF Biotyper

\section{Introduction}

The primary application of lactic acid bacteria (LAB) is related to preservation of food, but increasing relevance and contribution of these microorganisms in diverse sectors of food and pharmacy industries are observed. Moreover, this group of bacteria is an intrinsic factor in the production of various foodstuffs obtained through spontaneous fermentation.

Nowadays, LAB are widely used in food technology as commercial starter cultures. However, there is a need in the food industry to improve the properties of the starters used so far, whereas the 
development of novel fermented products (including new generation foodstuffs) often requires seeking new sources of microorganisms exhibiting desired technological and functional characteristics.

Extensive investigations have confirmed that food-derived LAB (in particular Lactiplantibacillus bacteria) exhibiting the ability to colonize the human intestine might play a significant role in its proper functioning. Additionally, there is a growing need to select new strains of bacteria with functional properties in order to improve food quality and broaden the range of fermented products, including probiotic ones [1]. Nevertheless, all microorganisms (especially new isolates) with the desired technological and functional potential have to be suitably tested to ensure the safety of application thereof in food industry. According to the guidelines recommended by FAO/WHO, any strains of bacteria that can potentially be used as food starter cultures and considered potentially probiotic must be thoroughly investigated. The initial phase of studies includes precise identification of the strain with phenotypic and genotypic methods. Modern molecular biology methods must be used to identify the genus, species, and strain of the microorganism in order to deposit it in the national culture collection [2].

Currently, new bacterial strains representing LAB are isolated and subjected to multidisciplinary investigations due to the constant need for finding useful microorganisms with valuable biotechnological, medical, and pharmaceutical potential and technological suitability for functional food production. This contributes to discovering new ecological niches, which are the sources of such bacteria with desired properties, e.g., health-promoting effects.

It is worth emphasizing that the fermentation process, based on natural microbiota consisting of autochthonous bacteria present in the environment and raw materials, often yields more satisfactory results than commercially available allochthonous starters [3]. Regrettably, most of the industrially available and widely used strains used for the fermentation of various plant-derived raw materials are allochthonous, and this type of microflora is not competitive with endogenous microbiota. In this regard, isolation and screening of LAB from spontaneously fermented foodstuff seem to be an interesting approach and a powerful means to obtain indigenous cultures useful for commercial applications [4].

Nowadays, mushrooms are recognized for their organoleptic characteristics as well as for their numerous bioactive substances which are beneficial and health-promoting [5]. Consumption of mushrooms has been found to exert a positive effect on fighting high blood pressure, high cholesterol, and even cancer [6,7]. Moreover, most edible mushrooms are perceived as a source of functional compounds, which, in combination with their low levels of fats and energy, makes them a great ingredient of a balanced diet [8]. It is also worth mentioning that in the dry mass of fruiting bodies of mushrooms, the content of bioavailable proteins is higher than that in most vegetables and fruits [5]. Nonetheless, relatively high protein concentration together with high enzymatic activity and low content of dry matter are the main factors influencing the low durability of mushroom fruiting bodies. However, some results suggest that LAB inoculates may be perceive as a proper strategy for improving the storage stability of spent mushroom (Pleurotus ostreatus) $[9,10]$. Hence, lacto-fermentation might constitute a desirable, biological method of preserving A. bisporus as an alternative to sterilization, canning, or pickling $[9,10]$.

At present, the process of lactic acid fermentation as a biological method for conservation of fungal fruiting bodies is not commonly used on an industrial scale, although this was a very popular way of extending the durability of mushroom raw material in the middle of the last century. This relatively cost- and time-efficient preservation method may be regarded as sustainable management of excess raw material. Moreover, such a bio-conservation process yields a product with more desirable characteristics than those in salted food, which is mainly associated with a reduction in nutrient losses and a possibility to lower the salt concentration in brine [5].

Unfortunately, there are not many research studies referring the lactic fermentation of the fruiting bodies of edible mushrooms fruits [5]. Even though A. bisporus is the most commonly consumed in the world, to our knowledge, the spontaneous fermentation process of this fungal raw material as well as the associated microflora have not been well characterized. 
Therefore, the aim of the investigation was the detecting and initial identification of lactic acid bacteria (LAB) isolated from spontaneously fermented fruiting bodies of white button mushrooms (A. bisporus) and further genetical analyses as well as selected functional properties of the chosen bacteria. Moreover, the preliminary study was also focused on the detection of isolates of LAB demonstrating the most favorable properties and the highest potential for application in lactic fermentation of $A$. bisporus, as this may contribute to further development of a new range of functional fermented products derived from fungal raw material.

\section{Materials and Methods}

\subsection{Spontaneous Fermentation of Fungal Raw Material}

The white button mushrooms (A. bisporus) used in the process of spontaneous fermentation were purchased from the company "Growing mushrooms-Pawelec Zdzisław" (Kazimierzówka 34, Świdnik, Poland). The mushrooms were collected in the morning, and the fruiting bodies were delivered to the laboratory on the same day (the research analysis began $3 \mathrm{~h}$ after harvesting). The mushrooms were washed under running (lukewarm) tap water, shredded into $2 \mathrm{~mm}$ thick slices, and flooded with a saline solution containing $2 \%(w / v) ~ N a C l$. After thorough mixing, the material was left until brine was released from the fruiting bodies through the exo-osmosis process. Then, the shredded mushrooms were divided into equal weight samples, which were transferred into sterile glass jars with a volume of $300 \mathrm{~mL}$ (three identical batches of fermentation material were prepared). Subsequently, the jars (containing mushrooms completely immersed in the brine) were tightly closed with lids and placed in a thermostatic chamber, where spontaneous fermentation was conducted $\left(28^{\circ} \mathrm{C}\right.$ for 5 days).

\subsection{Isolation and Selection of $L A B$ Isolates}

The procedure of bacteria isolation was performed according to [11] with some modifications. Briefly, $10 \mathrm{~g}$ of samples (containing the mushroom fruiting bodies with the brine) were collected from the fermented matrix and shaken for 5 min (Multi Speed Vortex MSV-3500, Biosan, Finland). Then, $1 \mathrm{~mL}$ of the liquid suspension was taken in order to prepare a series of consecutive dilutions in physiological saline. Thereafter, $100 \mu \mathrm{L}$ of the respective dilutions were collected, transferred to Petri dishes with previously prepared MRS agar (BioMaxima, Lublin, Poland), spread thoroughly on the medium surface, and incubated anaerobically at $37^{\circ} \mathrm{C}$ for $48 \mathrm{~h}$ (in duplicates). After the incubation, individual colonies of microorganisms (different from each other) were collected and again transferred to sterile de Man, Rogosa and Sharpe (MRS) agar (to ensure purity of the isolates, this stage of the procedure was performed twice).

Isolates capable of lactic acid production were detected with the plate method [11]. For this purpose, $1 \% \mathrm{CaCO}_{3}$ was added to MRS agar and, after inoculation, the tested isolates were incubated in anaerobic conditions $\left(24 \mathrm{~h} / 37^{\circ} \mathrm{C}\right)$. Acid-producing bacterial colonies (with a clean surrounding zone) were randomly selected from MRS plates and purified by replication on MRS agar plates.

The purified isolates (exhibiting acidification abilities) were maintained at $-80{ }^{\circ} \mathrm{C}$ in de Man, Rogosa and Sharpe (MRS) broth (Merck KGaA, Darmstadt, Germany) supplemented with $20 \%$ glycerol as stock cultures (to store tested collection of isolates). Prior to the analysis, each of the tested isolates was regularly transferred into fresh sterile broth MRS and incubated $\left(37^{\circ} \mathrm{C} / 18 \mathrm{~h}\right)$ in anaerobic conditions [12].

Microscopic observations, catalase tests, and Gram staining were performed for initial screening of Lactiplantibacillus $[13,14]$. Individual colonies of microorganisms were identified phenotypically by Gram staining. The catalase test was performed with the use of 3\% hydrogen peroxide solution that was dripped on single bacterial colonies (of each isolate) grown on MRS agar plates (no gas bubbles indicated catalase-negative microorganisms). Gram-positive, catalase-negative, bacilliform, and cocciform (spherical shape, bead-like chains) isolates were selected for further analysis. 


\subsection{Preliminary Identification of Isolates Using the MALDI-TOF Biotyper}

One hundred and ten isolates of LAB bacteria were subjected to identification using the MALDI-TOF Biotyper (Bruker Daltonics, Bremen, Germany). The identification was performed according to the method described by [15]. In brief, after $24 \mathrm{~h}$ of incubation, a single bacterial colony (of each isolate) was suspended in $150 \mu \mathrm{L}$ of sterile deionized water. In order to obtain homogenous mixtures, the suspensions were thoroughly mixed by vortexing. Thereafter, $96 \%$ ethanol $(450 \mu \mathrm{L})$ was added to each sample, which was further vortexed for $1 \mathrm{~min}$ and centrifuged $\left(8000 \times \mathrm{g} / 2 \mathrm{~min} / 4^{\circ} \mathrm{C}\right)$. After removing the supernatant, the step was repeated twice. Then, $40 \mu \mathrm{L}$ of a formic acid solution (70\%) were added to each sample, which was further vortexed. Subsequently, $40 \mu \mathrm{L}$ of $99 \%$ acetonitrile were added, and this was followed by vortexing $(1 \mathrm{~min})$ and centrifugation $\left(8000 \times \mathrm{g} / 2 \mathrm{~min} / 4^{\circ} \mathrm{C}\right)$. Samples for analysis ( $1 \mu \mathrm{L}$ for each isolate in three repetitions) were placed on a metal plate and left to dry in a sterile chamber at room temperature. Then, $1 \mu \mathrm{L}$ of HCCA- $\alpha$-Cyano-4-hydroxycinnamic acid $(10 \mathrm{mg} / \mathrm{mL})$ was applied on each spot of the sample and again left to dry. After the incubation (at ambient temperature), the plate was subjected to analysis in an UltrafleXtreme MALDI-TOF mass spectrometer (Bruker, Germany) with a $1000 \mathrm{~Hz}$ neodymium-doped yttrium aluminum garnet nitrogen laser (Nd-YAG). The determination was performed with the use of the MALDI Biotyper 3.0 software package (Bruker, Germany), where a score on a scale from 0 to 3.0 exhibited the level of identification probability.

A result above 2.0 implied reliable (unambiguous) identification of the genus and probable species identification.

In the study, L. plantarum DSM 20,174 was used as the reference strain (Leibniz Institut DSMZ-Deutsche Sammlung von Mikroorganismen und Zellkulturen GmbH, Germany).

\subsection{Comparison of the Selected Technological Functional Properties of Selected Autochthonous LAB}

\subsubsection{Ability of Isolates to Grow on Medium with an Alternative Carbon Source}

The composition of MRS agar was modified by replacing glucose with freeze-dried mushrooms $(2 \mathrm{~g} / \mathrm{L})$. The profile of saccharides in the used raw material has been further analyzed [16].

The sterile modified medium was inoculated by spreading $1 \%(\mathrm{vol} / \mathrm{wt})$ of the tested isolate cell suspension (prepared in sterile saline from culture in the exponential growth phase and adjusted to final $\mathrm{OD}_{600}=0.5$ ) on its surface. The inoculated Petri dishes (in triplicate for each analyzed LAB isolate) were incubated for $48 \mathrm{~h}$ at $37^{\circ} \mathrm{C}$ (in anaerobic conditions). Isolates that were able to form more than 30 colonies on the modified culture medium were considered capable of growth on an alternative carbon source (mushroom sugars). Isolates exhibiting such characteristics were marked with " + " and selected for the next stage of the investigations.

\subsubsection{Dynamics of Acidification of the Mushroom Material}

In order to determine the dynamics of the $\mathrm{pH}$ decrease in the mushroom material, fresh fruiting bodies of white button mushrooms were homogenized using a hand-blender to obtain homogeneous mass (smooth matrix). Then, samples containing the mushroom material were sterilized (by autoclaving) and inoculated by $1 \%(\mathrm{vol} / \mathrm{wt})$ of a bacterial cell suspension of a given LAB isolate (prepared in sterile saline from cultures in the exponential growth phase and adjusted to final $\mathrm{OD}_{600}=0.5$ ). The inoculated samples (in triplicate for each bacteria isolate) were incubated at $37^{\circ} \mathrm{C}$ (in anaerobic conditions). The $\mathrm{pH}$ value was measured after 3,7 , and $24 \mathrm{~h}$ of fermentation. Non-inoculated samples were a control variant.

\subsubsection{Detection of Isolates Able to Produce Exopolysaccharides}

The ability of the LAB isolates to synthesize exopolysaccharides (EPSs) was estimated with the method described by Manini et al. [17] with some modification. Briefly, the tested isolates were incubated on MRS agar plates for $48 \mathrm{~h}$ days at $37^{\circ} \mathrm{C}$. Triplicate plates containing 30 to 250 colonies (of each of the tested isolate) were evaluated for the ability to produce mucus. Colonies were assessed 
as capable of producing exopolysaccharides when the length of mucus strings stretching, as a result of single touching of the isolate colony with a wire-inoculating loop, was $5 \mathrm{~mm}$ (or more). The positive results were expressed as " + ", whereas "-" indicated that no mucus (characteristic exopolysaccharide consistency) was visible [18].

\subsubsection{Detection of Acid Tolerance in LAB Isolates}

The ability of bacteria to survive at low $\mathrm{pH}$ was evaluated in triplicate in two types of acidified MRS broths (at $\mathrm{pH}=3$ and $\mathrm{pH}=4)$ that were inoculated ( $1 \% \mathrm{vol} / \mathrm{vol})$ with bacterial cell suspensions. The optical density of the final cell concentration of each LAB isolate (in the exponential growth phase) used for inoculation of the $\mathrm{pH}$-adjusted MRS broths was approximately $\mathrm{OD}_{550}=0.125$. The tolerance to low $\mathrm{pH}$ of the environment was evaluated by measuring OD550 after incubation $\left(24 \mathrm{~h}\right.$ at $37^{\circ} \mathrm{C}$ in anaerobic conditions). Tested microorganisms with cell suspensions exhibiting $\mathrm{OD}_{550}$ of 0.5 (or higher) after incubation were regarded as resistant to low $\mathrm{pH}$.

\subsubsection{Hydrophobicity of Bacterial Cells}

Hydrophobicity of the cellular surface was determined with the method described by Pérez-Sánchez et al. [19]. After incubation in MRS broth $\left(24 \mathrm{~h}\right.$ at $37^{\circ} \mathrm{C}$ in anaerobic conditions), the biomass of the analyzed LAB isolates was collected in the stationary phase by centrifugation $\left(6000 \times \mathrm{g} / 5 \mathrm{~min} / 4^{\circ} \mathrm{C}\right)$. After removing the supernatants, the pellets were washed twice with phosphate buffer ( $\mathrm{pH}$ 6.5) and suspended (in the same buffer) to obtain all bacterial cell suspensions with optical density $\left(\mathrm{OD}_{560}\right)$ adjusted to 1.0. Subsequently, $3 \mathrm{~mL}$ of the suspensions of bacterial cells were transferred into sterile tubes and $1 \mathrm{~mL}$ of toluene (Chempur, Piekary Ślaskie, Poland) was added to each sample. Then, the samples were vortexed for $120 \mathrm{~s}$ and left at $37^{\circ} \mathrm{C}$ for $1 \mathrm{~h}$ in order to separate the formed two phases. The aqueous phase was collected and optical density was measured at $560 \mathrm{~nm}$.

Cell hydrophobicity was calculated as the mean percentage decrease in the optical density $\left(\mathrm{OD}_{560}\right)$ of the suspension of the isolates caused by adhesion of bacterial cells to the applied hydrocarbon according to the following formula:

$$
\mathrm{H}[\%]=\left[\left(\mathrm{OD}_{560}(\text { initial })-\mathrm{OD}_{560}(\text { with toluene })\right) /\left(\mathrm{OD}_{560}(\text { initial })\right] \times 100\right.
$$

where $\mathrm{OD}_{560}$ (initial) and $\mathrm{OD}_{560}$ (with toluene) are the absorbances before and after the extraction with toluene, respectively.

\subsubsection{Ability to Hydrolyze Bile Salt}

The activity of the analyzed bacteria to hydrolyze bile salt was determined using the method described by Gomes et al. [20] with some modifications. The tested isolates were incubated in MRS broth for $12 \mathrm{~h}$ and subsequently, bacterial biomasses were collected by centrifugation $\left(8000 \times g / 15 \mathrm{~min} / 4{ }^{\circ} \mathrm{C}\right)$ and washed twice with sterile physiological saline. Then, the suspensions of cell cultures $\left(\mathrm{OD}_{550}=0.5\right)$ were prepared and spread $(10 \mathrm{~mL})$ on the surface of MRS agar containing $0.5 \%$ of taurodeoxycholic acid (Sigma-Aldrich, Arklow, Ireland). Afterwards, the MRS agar plates were incubated for $48 \mathrm{~h}$ days at $37^{\circ} \mathrm{C}$ (in anaerobic conditions). The ability of the isolates to hydrolyze bile salt was detected based on the presence of visible precipitation zones around the colonies [21].

\subsection{Further Molecular and Biochemical Analysis of Selected LAB Isolates}

\subsubsection{S rRNA Gene Sequencing Analysis}

Isolates that were capable of growing at low $\mathrm{pH}$ and on a medium with an alternative carbon source exhibiting the ability to produce exopolysaccharides as well as acid and bile salt tolerance were selected for further analysis. This included the identification of tested LAB isolates (to the species level) as well as comparison of the profiles of carbohydrate metabolism by API $50 \mathrm{CH}$ identification system 
(Biomerieux, Marcy l'Etoile France), which was used according to the manufacturer's instructions. Moreover, molecular analysis was also performed. Extraction of genomic DNA from pure cultures was performed using Genomic Mini AX Bacteria Spin (A\&A Biotechnology, Gdynia, Poland) according to the manufacturer's protocol. The purity and concentration of the extracted genomic material was determined spectrophotometrically (NanoDrop 2000, Thermo Scientific, Wilmington, DE, USA).

Sequences coding for $16 \mathrm{~S}$ ribosomal RNA were amplified using the universal primers (27f) 5'-AGAGTTTGATCCTGGCTCAG-3' , and (1495r) 5'-CTACGGCTACCTTGTTACGA-3' (Genomed S.A., Warsaw, Poland). The PCR reaction was performed according to Gustaw et al. [15]. The PCR reaction mixture $(25 \mu \mathrm{L})$ contained $100 \mathrm{ng} \mu \mathrm{L}$ of purified chromosomal DNA, 20 pmol of each primer, $12.5 \mu \mathrm{L}$ of DreamTaq Green PCR Master Mix (2×) (Thermo Scientific, Waltham, MA, USA), and nuclease-free water (adjusted to the final volume).

The amplification was performed in a Labcycler (SensoQuest, Göttingen, Germany) using a program consisting of the following steps: denaturation $\left(4 \mathrm{~min} / 95^{\circ} \mathrm{C}\right), 30$ cycles including denaturation at $95{ }^{\circ} \mathrm{C} / 30 \mathrm{~s}$, annealing at $48{ }^{\circ} \mathrm{C} / 30 \mathrm{~s}$, and elongation $\left.72{ }^{\circ} \mathrm{C} / 30 \mathrm{~s}\right)$, and final extension $\left(8 \mathrm{~min} / 72{ }^{\circ} \mathrm{C}\right)$ followed by cooling the samples up to $4{ }^{\circ} \mathrm{C}$. The amplification products were electrophoretically separated in $1 \%$ agarose gel (Eurx, Gdansk, Poland) containing $0.25 \%$ Midori Green DNA Stain (Nippon Genetics Europe, Dueren, Germany). The electrophoresis was conducted in TBE buffer for $1.5 \mathrm{~h}$ at $60 \mathrm{~V}$, visualized under UV illumination, and photographed with a digital camera (Gel Doc XR+ Imaging System, BioRad, Waltham, MA, USA).

Amplicons were purified and sequenced with a BigDye Terminator v3.1 Cycle Sequencing Kit (Applied Biosystems, USA) using the capillary 3730xl DNA Analyzer sequencing system (Applied Biosystems, USA). Thereafter, the nucleotide sequences were subjected to further bioinformatic analyses using a DNA Baser Sequence, and BLAST was applied to align the sequences (National Center for Biotechnology Information, Bethesda, MD, USA,). Afterwards, the sequences were compared with sequences available in the GenBank database.

\subsubsection{Species-Specific Multiplex-PCR}

To distinguish the L. plantarum (Lactiplantibacillus plantarum subsp. plantarum according to new classification), L. pentosus (Lactiplantibacillus pentosus according to new classification), and L. paraplantarum (Lactiplantibacillus pentosus according to new classification) isolates, the Multiplex PCR technique was employed in accordance with Torriani et al. [22] with the use of the specific primers: pREV (5'-TCGGGATTACCAAACATCAC-3'), pentF (5'-CAGTGGCGCGGTTGATATC- $\left.3^{\prime}\right)$, paraF ( $5^{\prime}$-GTCACAGGCATTACGAAAAC-3'), and planF (5'-CCGTTTATGCGGAACACCTA-3'). The oligonucleotides were synthesized by Genomed S.A. (Warsaw, Poland). The PCR products were subjected to electrophoresis, which was conducted in conditions corresponding to those mentioned above.

\subsection{Statistical Analysis}

Statistical analysis was performed using the STATISTICA 13.1 program (StatSoft, Inc., Tulsa, OK, USA), applying Tukey's HSD test in analysis of variance (ANOVA) to estimate the significance of the differences between the mean values at $p<0.05$.

\section{Results}

\subsection{Identification of Autochthonous LAB in Spontaneously Fermented A. bisporus}

The detected LAB isolates (Gram-positive, catalase-negative bacteria with an ability to produce lactic acid, bacilli, and cocci with a spherical shape, including bead-like chains) were subjected to initial identification using the MALDI-TOF Biotyper. The identification of the LAB species was based on the alignment of obtained spectra of isolates with the Bruker database (identification over two points within a triple repetition of the experiment was considered highly probable). 
The analysis indicated that 58 spectra (which constitutes $52.73 \%$ of the isolated LAB) corresponded to Ln. mesenteroides, $26.36 \%$ to Lc. lactis, while $18.18 \%$ exhibited high probability to represent L. plantarum and only three spectra (that is $2.73 \%$ that) were identified as L. paraplantarum (Table 1 ). The results revealed the dominance of $L n$. mesenteroides in the environment of the spontaneously fermented white button mushrooms.

Table 1. Species identification (MALDI-TOF Biotyper) and comparison of the characteristics of lactic acid bacteria (LAB).

\begin{tabular}{|c|c|c|c|c|c|c|c|c|}
\hline \multirow[b]{2}{*}{$\begin{array}{l}\text { Isolate } \\
\text { ID * }\end{array}$} & \multirow[b]{2}{*}{$\begin{array}{l}\text { Morphological } \\
\text { Form (Shape) }\end{array}$} & \multirow[b]{2}{*}{$\begin{array}{l}\text { Gram } \\
\text { Stain }\end{array}$} & \multirow[b]{2}{*}{$\begin{array}{c}\text { Lactic } \\
\text { Acid } \\
\text { Production }\end{array}$} & \multirow[b]{2}{*}{$\begin{array}{l}\text { Catalase } \\
\text { Reaction }\end{array}$} & \multirow[b]{2}{*}{$\begin{array}{c}\text { Species ** } \\
\text { Identified by } \\
\text { MALDI-TOF }\end{array}$} & \multicolumn{3}{|c|}{ Growth in } \\
\hline & & & & & & $\begin{array}{c}\text { MRS } \\
\text { Broth at } \\
\mathrm{pH}=3\end{array}$ & $\begin{array}{l}\text { MRS } \\
\text { Broth at } \\
\mathrm{pH}=4\end{array}$ & $\begin{array}{l}\text { MSodified } \\
\text { MRS Agar }\end{array}$ \\
\hline $\begin{array}{l}\text { EK1, E56, E57, E58, } \\
\text { E59, E60, E61 }\end{array}$ & $\mathrm{R}$ & $\mathrm{P}$ & + & - & $\begin{array}{l}\text { Lactiplantibacillus } \\
\text { plantarum }\end{array}$ & + & + & - \\
\hline EK2, E14 & $\mathrm{R}$ & $\mathrm{P}$ & + & - & $\begin{array}{l}\text { Lactiplantibacillus } \\
\text { plantarum }\end{array}$ & - & + & + \\
\hline $\begin{array}{c}\text { EK3, EK5, EK6, EK10, } \\
\text { EK11, EK12, EK13, } \\
\text { EK15, EK51, EK55, } \\
\text { E62 }\end{array}$ & $\mathrm{R}$ & $\mathrm{P}$ & + & - & $\begin{array}{l}\text { Lactiplantibacillus } \\
\text { plantarum }\end{array}$ & + & + & + \\
\hline $\begin{array}{c}\text { EK7, EK8, EK9, E21, } \\
\text { E22, E26, E65, E66, } \\
\text { E67, E100, E101, E102, } \\
\text { E103, E104, } \\
\text { E120, E121, } \\
\text { E122, E123, } \\
\text { E124, E73B, E125, } \\
\text { E126, E127, E128 }\end{array}$ & $\mathrm{C}$ & $\mathrm{P}$ & + & - & Lactococcus lactis & - & - & - \\
\hline $\begin{array}{c}\text { E64, } \\
\text { E68, E74B, } \\
\text { E75B }\end{array}$ & $\mathrm{C}$ & $\mathrm{P}$ & + & - & Lactococcus lactis & - & - & + \\
\hline E79A & $\mathrm{C}$ & $\mathrm{P}$ & + & - & Lactococcus lactis & + & + & - \\
\hline $\begin{array}{c}\text { E23, } \\
\text { E24A, E25, E96C, E76B }\end{array}$ & $\mathrm{C}$ & $\mathrm{P}$ & + & - & $\begin{array}{c}\text { Leuconostoc } \\
\text { mesenteroides }\end{array}$ & - & - & - \\
\hline $\begin{array}{l}\mathrm{E} 88 \mathrm{~B}, \\
\mathrm{E} 72 \mathrm{C}\end{array}$ & $\mathrm{C}$ & $\mathrm{P}$ & + & - & $\begin{array}{l}\text { Leuconostoc } \\
\text { mesenteroides }\end{array}$ & + & + & + \\
\hline $\begin{array}{c}\text { E71C, E76C, } \\
\text { E79C, E80C, E81B, } \\
\text { E82B, E83B, E84A, } \\
\text { E96C, E71A, } \\
\text { E73A, E72A, } \\
\text { E74A, E75A, } \\
\text { E76A, E78A, } \\
\text { E71B, E84B, } \\
\text { E93C, E94C, } \\
\text { E95C, E81A, } \\
\text { E83A, E82A, } \\
\text { E80A, E86B, } \\
\text { E73C, E78B, E77B, } \\
\text { E77A, } \\
\text { E79B, E80B, E89B, } \\
\text { E74C, E75C, E78C, } \\
\text { E81C, E82C, } \\
\text { E83C, E84C, E72B, } \\
\text { E85C, } \\
\text { E86C, E87C, } \\
\text { E88C, E89C, } \\
\text { E90C, E91C, } \\
\text { E92C, E87B, } \\
\text { E85B }\end{array}$ & $\mathrm{C}$ & $\mathrm{P}$ & + & - & $\begin{array}{l}\text { Leuconostoc } \\
\text { mesenteroides }\end{array}$ & - & - & + \\
\hline E53, E54 & $\mathrm{R}$ & $\mathrm{P}$ & + & - & $\begin{array}{l}\text { Lactiplantibacillus } \\
\text { paraplantarum }\end{array}$ & - & - & + \\
\hline EK4 & $\mathrm{R}$ & $\mathrm{P}$ & + & - & $\begin{array}{l}\text { Lactiplantibacillus } \\
\text { paraplantarum }\end{array}$ & + & + & + \\
\hline
\end{tabular}

Explanatory notes: * Isolate name; ${ }^{* *}$ according to the classification [23], Lactobacillus plantarum has been renamed to Lactiplantibacillus plantarum subsp. plantarum; R-rod; C-cocci spherical shape (bead-like chains); P-positive results of Gram staining; "+" means that the isolate exhibited the ability; "_" means lack of the ability. 
The isolates exhibited various levels of acid tolerance and a diverse ability to grow on an alternative source of carbon derived from fungal sugars (Table 1). It was noticed that all Lc. lactis strains were sensitive to low $\mathrm{pH}$ values of the environment, except for E79. Moreover, only four isolates (E64, $\mathrm{E} 68, \mathrm{E} 74 \mathrm{~B}, \mathrm{E} 75 \mathrm{~B})$ of all the Lc. lactis isolates were able to grow on the modified MRS agar (Table 1). The $\mathrm{Ln}$. mesenteroides isolate showed a comparably low tolerance to the low value of $\mathrm{pH}$. Furthermore, only E88B and E72C of Ln. mesenteroides were able to grow in the medium at $\mathrm{pH} 3$ and $\mathrm{pH} 4$. However, in contrast to Lc. lactis, the majority of Ln. mesenteroides isolates (52 out of 58) exhibited the ability to grow in the medium containing the fungal material as a substitute of regular glucose. In turn, the L. plantarum isolates were characterized by significantly higher tolerance to low $\mathrm{pH}$ and only EK2 and $\mathrm{E} 14$ were not able to grow at $\mathrm{pH}=3$. Additionally, $60 \%$ of all the L. plantarum isolates had an ability to grow on the modified medium (Table 1).

The obtained results of analysis (tolerance to low $\mathrm{pH}$ values and growth on modified medium) facilitated the selection of isolates intended for the further stages of the study focused on analysis of their probiotic characteristics and comparison of the acidification properties exhibited by the bacteria during mushroom fermentation.

Comparison of the rate of the decrease in the $\mathrm{pH}$ of the fungal material fermented by the selected bacteria isolates indicated that the isolates differed in terms of acidifying properties. The highest acidification dynamics were observed in isolates EK55 and EK4, which, after $24 \mathrm{~h}$ of incubation, were able to decrease the $\mathrm{pH}$ of the raw material up to $5.06 \pm 0.021$ and $5.17 \pm 0.015$, respectively (Table 2). However, none of the microorganisms were able to reduce the $\mathrm{pH}$ value (in the experimental conditions) of the fermented material up to $\mathrm{pH}<5$.

Table 2. Comparison of selected functional properties.

\begin{tabular}{|c|c|c|c|c|c|c|}
\hline \multirow{2}{*}{ Isolate } & \multicolumn{3}{|c|}{ pH of Mushroom Material Fermented by the Isolate } & \multirow{2}{*}{$\begin{array}{l}\text { Ability to EPS } \\
\text { Production }\end{array}$} & \multirow{2}{*}{$\begin{array}{c}\text { Ability to } \\
\text { Hydrolyze Bile Salt }\end{array}$} & \multirow{2}{*}{$\begin{array}{c}\text { Cell } \\
\text { Hydrophobicity [\%] }\end{array}$} \\
\hline & After $3 \mathrm{~h}$ & After $7 \mathrm{~h}$ & After $24 \mathrm{~h}$ & & & \\
\hline EK3 & $6.27 \pm 0.07 \mathrm{abB}$ & $6.33 \pm 0.012$ efB & $6.02 \pm 0.026^{\mathrm{jA}}$ & + & + & $0.34 \pm 0.292^{a}$ \\
\hline EK4 & $6.36 \pm 0.052$ cdefB & $6.35 \pm 0.010 \mathrm{fgB}$ & $5.17 \pm 0.015^{\mathrm{bA}}$ & + & + & $25.34 \pm 0.407^{\mathrm{e}}$ \\
\hline EK5 & $6.37 \pm 0.025^{\text {cdefC }}$ & $6.29 \pm 0.010 \mathrm{bcdB}$ & $6.20 \pm 0.015^{\mathrm{kA}}$ & + & + & $27.33 \pm 1.516^{\mathrm{f}}$ \\
\hline EK6 & $6.30 \pm 0.021$ abcdA & $6.39 \pm 0.006^{\mathrm{hA}}$ & $5.70 \pm 0.010^{\mathrm{eA}}$ & + & + & $0.37 \pm 0.112^{\mathrm{a}}$ \\
\hline EK10 & $6.42 \pm 0.053 \mathrm{aC}$ & $6.23 \pm 0.006^{\mathrm{cdeB}}$ & $5.69 \pm 0.010 \mathrm{gA}$ & - & + & n.d. \\
\hline EK11 & $6.54 \pm 0.089 \mathrm{abcB}$ & $6.19 \pm 0.006^{\mathrm{bcdB}}$ & $5.71 \pm 0.010^{\mathrm{hA}}$ & - & - & n.d. \\
\hline EK12 & $6.39 \pm 0.055^{\mathrm{efB}}$ & $6.34 \pm 0.010$ efgB & $5.40 \pm 0.015^{\mathrm{cA}}$ & + & + & $29.59 \pm 0.700^{g}$ \\
\hline EK13 & $6.39 \pm 0.026^{\operatorname{defB}}$ & $6.37 \pm 0.010 \mathrm{ghB}$ & $6.01 \pm 0.021 \mathrm{jA}$ & + & + & $0.11 \pm 0.113^{a}$ \\
\hline EK15 & $6.48 \pm 0.071 \mathrm{bcdeC}$ & $6.21 \pm 0.006^{\mathrm{abB}}$ & $5.70 \pm 0.010^{\mathrm{fA}}$ & + & + & $4.66 \pm 0.918^{b}$ \\
\hline EK51 & $6.34 \pm 0.006^{\text {bcdefC }}$ & $6.28 \pm 0.010^{a b c B}$ & $5.79 \pm 0.010^{\mathrm{fA}}$ & + & + & $8.83 \pm 0.104^{c}$ \\
\hline EK55 & $6.35 \pm 0.006^{\text {bcdef } B}$ & $6.32 \pm 0.015^{\mathrm{efB}}$ & $5.06 \pm 0.021^{\mathrm{aA}}$ & + & + & $28.75 \pm 0.551^{\mathrm{fg}}$ \\
\hline E62 & $6.31 \pm 0.012^{\mathrm{abcd} A}$ & $6.29 \pm 0.006^{\mathrm{bcB}}$ & $5.94 \pm 0.010^{\mathrm{iA}}$ & + & + & $1.52 \pm 0.435^{\mathrm{a}}$ \\
\hline $\mathrm{E} 24 \mathrm{~A}$ & $6.34 \pm 0.017$ bcdeB & $6.27 \pm 0.015^{b c d B}$ & $5.77 \pm 0.006^{\mathrm{fgA}}$ & + & - & n.d. \\
\hline E72C & $6.34 \pm 0.006^{\text {bcdeB }}$ & $6.32 \pm 0.010 \operatorname{def} B$ & $5.54 \pm 0.010 \mathrm{dA}$ & + & - & $16.63 \pm 2.217^{\mathrm{d}}$ \\
\hline E79B & $6.29 \pm 0.017^{\mathrm{abcB}}$ & $6.27 \pm 0.006^{\mathrm{abB}}$ & $5.67 \pm 0.010^{\mathrm{eA}}$ & - & - & n.d. \\
\hline E88B & $6.35 \pm 0.035$ bcdefC & $6.25 \pm 0.006^{\mathrm{aB}}$ & $5.68 \pm 0.010^{\mathrm{eA}}$ & + & - & $14.68 \pm 0.151^{\mathrm{d}}$ \\
\hline Control & $6.43 \pm 0.017^{\mathrm{fB}}$ & $6.42 \pm 0.010 \mathrm{iAB}$ & $6.4 \pm 0.010^{1 \mathrm{~A}}$ & & & \\
\hline
\end{tabular}

Explanation notes: The results are given as mean values \pm standard deviation $(x \pm s / S D ; n=5)$. The following uppercase letters $(\mathrm{A}-\mathrm{C})$ express significant differences $(p<0.05)$ in the same row, while the lowercase letters $(\mathrm{a}-1)$ express significant differences $(p<0.05)$ between values in the same column; n.d. - not detected (value below $0.1 \%$ ).

Isolates that were able to growth in MRS broth at $\mathrm{pH}=3, \mathrm{pH}=4$ as well as on modified MRS agar and exhibited the desirable properties (including the EPS production and bile salt hydrolysis ability presented in Table 2) were subjected to further molecular analysis based on of the analysis the sequence of the conservative gene (see Table S1 in Supplementary Materials).

Most of analyzed sequences of products of amplification 16S rRNA exhibited similarity to L. plantarum (isolates EK3, EK5, EK12, E13, EK15, EK51, EK55, E62), while EK4 and EK6 exhibited affinity to bacteria L. paraplantarum (see Table S1 in Supplementary Materials).

The results of the multiplex PCR (recA gene) revealed the presence of amplicons with a length of approximately $300 \mathrm{bp}$ (that is characteristic for L. plantarum) in eight of ten analyzed bacteria isolates, while 100-bp PCR products were identified only in two samples (isolates EK4 and EK6) that 
indicate affinity to L. paraplantarum (see Figure S1 in Supplementary Materials). The phenotypic test based on carbohydrate fermentation profiles (API $50 \mathrm{CH}$ ) classified the tested isolates to L. plantarum; however, some differences in the biochemical profiles were observed (see Table S2 in Supplementary Materials). Among the analyzed bacteria, six various patterns of metabolic profiles were noted. The same carbohydrate fermentation profiles showed isolates EK51 and E62. Other isolates that exhibited similar profile were EK55 and EK12. The third group was represented by EK3, EK5, and EK15. In contrast, the remaining isolates (EK4, EK6, and EK13) formed separate profiles (three different patterns of carbohydrate fermentation). It is worth noting that the analysis of 16Sr RNA sequences and the results of the performed multiplex PCR indicated the affinity of EK4 and EK6 isolates to L. paraplantarum (that may explain their distinctiveness and considerable differences in profiles of carbohydrate metabolism). Additionally, in the case of EK4, this identification was confirmed by MALDI-TOF Biotyper analysis.

The results indicate the necessity to perform further, more extensive analyses to determine whether the isolates tested with the same profiles are different strains.

\subsection{Comparison of the Selected Technological Functional Properties of Selected Autochthonous LAB}

For investigation of the selected functional properties, isolated bacteria that exhibited tolerance to low $\mathrm{pH}$ values (at $\mathrm{pH}=3$ and $\mathrm{pH}=4$ ) and an ability to grow on modified MRS agar were chosen from all initially identified (MALDI-TOF) isolates.

The assessment of the ability of the examined microorganisms to hydrolyze bile salts revealed that only five isolates (L. plantarum EK11, Ln. mesenteroides E24A, Ln. mesenteroides E72C, Ln. mesenteroides E79B, Ln. mesenteroides E88B) did not exhibit such activity (Table 2). In turn, only three (L. plantarum EK11, L. plantarum EK10, Ln mesenteroides E79B) were recognized as EPS non-synthesizing bacteria. Moreover, the analysis of bacterial cell hydrophobicity indicated that all isolates without the capability of exopolysaccharide production and Ln. mesenteroides E24A exhibited a hydrophobicity level below $0.1 \%$. In contrast, the highest values of this parameter were noted for L. plantarum isolates EK12 $(29.59 \pm 0.7 \%)$, EK55 (28.75 $\pm 0.551 \%)$, and EK5 $(27.33 \pm 1.516 \%)$.

The comparison of the ability to hydrolyze bile salt revealed that not all the $\mathrm{Ln}$. mesenteroides isolates demonstrated metabolic activity, ensuring viability in the medium containing $0.5 \%$ of bile salts. In contrast, the L. plantarum isolates (with the exception of EK11) were characterized by a significantly higher ability to hydrolyze bile salts (Table 2).

\section{Discussion}

\subsection{Identification and Screening of Autochthonous LAB in Spontaneously Fermented A. bisporus}

Greater awareness of the importance of diet and its impact on human health contributes to changes in dietary habits. This significantly increases consumers' concern with the choice of purchased and consumed food products. It is currently observed that natural and traditional products with a reduced amount of chemical and synthetic substances added at various production stages are desired. For this reason, traditional fermented products (especially plant-based products) are perceived as food with additional desirable pro-health benefits. Moreover, the rising demand for such products is associated with their unique characteristics, which are attributable to traditional production as well as distinctive sensory and organoleptic properties. Furthermore, the application of the starter cultures with probiotic properties rather than regular starter cultures in the food industry may offer additional advantages and may be an interesting approach to enhancement of the use of the industrial process of lactic acid fermentation and production of more health-oriented foods [24,25].

There is ample evidence that the fermentation processes of some food products are carried out by characteristic and innovative starter cultures, which contribute to create the specific and unique characteristics of this type of foodstuff. However, there are no commercial starter cultures (especially with potential health-promoting properties) intended for the fermentation of plant- and 
mushroom-derived raw materials [25-27]. Therefore, this study was focused on the detection and identification of LAB from spontaneously fermented fruiting bodies of white button mushrooms (A. bisporus). The selected microorganisms were subjected to preliminary analysis determining some of their functional properties in order identify isolates with the most favorable properties and the highest potential of application as starter cultures (also suitable for lactic acid fermentation of fungal raw material).

The MALDI-TOF identification of the microorganisms indicated the presence of the following LAB species: Lactococcus lactis, Leuconostoc mesenteroides, Lactiplantibacillus paraplantarum, and Lactiplantibacillus plantarum, with the predominance of Leuconostoc mesenteroides. A similar observation was described by other authors, who also noted that the predominance of Ln. mesenteroides rapidly declines with the progress of fermentation, due to the sensitivity of these bacteria to low $\mathrm{pH}$ acidic conditions [24,28]. Similarly, in analysis of autochthonous functional starter cultures in traditionally produced sauerkraut, Beganović et al. [25] noticed that after three days of fermentation with recorded decline in the $\mathrm{pH}$ value, the dominant $\mathrm{Ln}$. mesenteroides were replaced by L. plantarum and other LAB that completed the process of fermentation. Moreover, it was demonstrated that $L n$. mesenteroides subsp. mesenteroides, belonging to the heterofermentative LAB group, initiates the fermentation of sauerkraut through reducing $\mathrm{pH}$ during the production of lactic and acetic acids with a simultaneous reduction in the oxygen level through carbon dioxide production. This bacterium has a considerable influence on the taste, aroma, and quality of fermented cabbage as well $[25,29]$. This suggests that the prevalence of Ln. mesentoroides (noted also in our analysis of spontaneous fermented mushroom material) contributes, to a considerable extent, to the development of organoleptic characteristics of the fermented mushroom-derived products.

The phylogenetic relationships and taxonomic positions of diverse species that possess similar content of GC and exhibit the same nucleotide frequencies can be determined with the use of nucleotide sequences $[22,30]$. However, it was revealed in the case of some closely related species that the analysis of $16 \mathrm{~S}$ rRNAs might not be sufficient to provide information on recent evolutional changes (mutations), since they are too recent to be fixed in such slowly diverging sequences [22]. As suggested in scientific reports, the amplification and sequencing of the 16S rRNA gene is often not sufficient to identify and distinguish L. plantarum, L. paraplantarum, and L. pentosus. Therefore, the species-specific multiplex-PCR proposed by Torriani et al. [22] was implemented in our investigations (since recA can tolerate mutations that either do not or only slightly alter its products). The results of the analysis proved that all the multiplex PCR products were specific to L. plantarum species, except EK4 and EK6 that exhibited affinity to L. paraplantarum.

\subsection{Comparison of the Selected Technological and Functional Properties of the Chosen Autochthonous LAB}

The results of the preliminary analysis (ability of the isolates to grow on medium with an alternative carbon source containing mushroom-derived material and the dynamics of acidification of the mushroom material during fermentation) suggest that some of the tested endogenous isolates of LAB (especially L. plantarum EK55 and L. paraplantarum EK4) can potentially be applied for the formulation of starter cultures (monoculture or component of multicultural composition) suitable for the lactic acid fermentation of plant or fungal raw material.

One of the main parameters determining the properties of fermented food is the $\mathrm{pH}$ value, which not only influences the flavor but also has an effect on the microbiological stability against pathogens and prevents food quality deterioration [31]. L. plantarum is perceived as the most acid tolerant species predominant in sauerkraut fermentation, especially in the late homofermentative phase of this process [32,33]. However, it was noticed that none of the tested autochthonous bacterial isolates from white button mushrooms were able to reduce the $\mathrm{pH}$ of the fermented product below 5 after $24 \mathrm{~h}$ at $37^{\circ} \mathrm{C}$. This might be a consequence of the insufficient time of incubation (too short a fermentation process) or an inadequate dose of inoculum for the fermentation of this type of raw material. Khaskheli et al. [34] noted that $\mathrm{pH}$ value of Auricularia auricular fermented at $26 \pm 4{ }^{\circ} \mathrm{C}$ for about 3 to 4 weeks 
reached from 4.5 to 5.5. Probably, a longer time of fermentation would have resulted in $\mathrm{pH}<5$ of the fermented fruiting bodies of white button mushrooms (A. bisporus).

The selected isolates were analyzed in order to evaluate the desirable features (including resistance to bile salt, acidic tolerance, hydrophobicity) in LAB probiotics. The investigations revealed that 11 of the 16 isolates were able to grow on MRS agar containing $0.5 \%$ of bile salts. It is worth mentioning that supplementation of the medium with bile salts up to $0.3 \%$ is deemed to be critical and sufficiently high to screen for resistant strains $[35,36]$. The results indicate that Ln. mesenteroides (E24A, E72C, E79B, E88B) and L. plantarum EK11 were sensitive to analyzed bile salts concentration.

It has been suggested that bacterial cell hydrophobicity is influenced by the ability to synthesize exopolysaccharides [37]. It is also claimed that extracellular proteins in EPSs have major relevance in the protective function, as they contribute to the bacterial surface hydrophobicity [38]. The results of the estimation of the ability of the tested isolates to produce exopolysaccharides suggested that EPS non-producing bacteria were also characterized by very low cell hydrophobicity (below $0.1 \%$ ). This is in agreement with results described by Xia et al. [38], who analyzed extracellular polymeric substances protecting Escherichia coli from organic solvents and found that an increase in hydrophobicity was correlated with differences in EPS content.

The results obtained in our study suggest that especially L. plantarum (EK5, EK12, EK55) and L. paraplantarum EK4 can be further analyzed to determine their potential applications in the fermented food industry as starter cultures. Moreover, in this preliminary study, these microorganisms exhibited survivability at low $\mathrm{pH}$, high hydrophobicity of the bacterial cell, ability to produce EPS, and ability to hydrolyze bile salt, which represent part of the desired probiotic properties. Therefore, the obtained findings of this preliminary study have particular importance especially in regards to the possibility of the application of a biological preservation of mushroom fruiting bodies by lactic acid fermentation using determined LAB isolates, which currently is not popular or developed on an industrial scale [5].

The application of selected LAB isolates provides a proper and repeatable fermentation process. Additionally, lactic fermentation is expected to improve the health values of the mushrooms at the same time through the presence of viable lactic acid bacteria. The promising results of this preliminary research prompt further extensive analyses of the identified autochthonous LAB isolated from the spontaneously fermented fruiting bodies of white button mushrooms. Therefore, the technological and functional features exhibited by isolated LAB have to be further studied in the food system (in various food matrixes, including mushrooms- and plant-derived raw materials or even milk). It should be also verified whether these are different strains and, if so, the level of their diversity should be assessed. Additionally, their properties as a probiotic starter culture should be determined in terms of their application in the production of plant- and mushroom-based functional foodstuff.

Moreover, due to the fact that nowadays, the application of technologically functionalized starter cultures is more desirable (because of the greater survivability and viability of the microorganisms in environmental conditions) [39,40], developing a proper form of starter cultures, allowing the maintenance of appropriate levels of bacteria activity in the material subjected to the fermentation process, is a great challenge and subject of prospective study.

\section{Conclusions}

The findings of the initial study exhibit that spontaneously fermented A. bisporus fruiting bodies may be an alternative source of new LAB isolates exhibiting adaptation to the acidic environment and desirable functional properties that may contribute to development of potentially probiotic starter cultures. Among autochthonous LAB (isolated from the tested mushroom raw material), Ln. mesenteroides predominated in spontaneously fermented A. bisporus, while L. paraplantarum, L. plantarum, and Lc. lactis were less abundant. Considering the parameters analyzed in the research, isolates EK55 and EK4 exhibited desired features as well as functional and technological potential; therefore, they are intended for further research analyzing these bacteria's suitability in the formulation of novel starter cultures. However, there is still a need to continue the study via a wide range of 
interdisciplinary analyses for full characterization of the isolates at the strain level (unambiguously differentiating the strains with exhibited by them desired features) and verify their technological and functional properties determining their further applications.

Supplementary Materials: The following are available online at http://www.mdpi.com/2304-8158/9/11/1631/s1. Table S1: The results of comparison of the obtained 16S rRNA sequences of analyzed isolates with sequences available in the GenBank database.; Table S2: The comparison of the profiles of carbohydrate fermentation exhibited by the tested isolates.; Figure S1: Electrophoretic separation the products of amplification recA gene (line M1 and M2-molecular markers expressing mass in bp; line 1-negative control sample; line 2-EK3; line 3-EK4; line 4-EK5; line 5-EK12; line 6-EK15; line 7-EK13; line 8-EK51; line 9-EK6; line 10-EK55; line11-E62).

Author Contributions: Conceptualization, K.S. and K.G.; methodology, K.G., A.S. and K.S.; software, W.G.; validation, W.G., E.J.-R. and A.S.; formal analysis, K.S., A.S, E.J.-R. and K.G.; investigation, K.S. and K.G.; resources, A.S.; data curation, W.G.; writing — original draft preparation, K.S.; writing-review and editing, K.S. and K.G.; visualization, A.S.; supervision, W.G. and S.W.; project administration, E.J.-R.; funding acquisition, E.J.-R. All authors have read and agreed to the published version of the manuscript.

Funding: This research was funded by Project financed under the program of the Minister of Science and Higher Education under the name "Regional Initiative of Excellence" in 2019-2022 project number 029/RID/2018/19 funding amount 11927 330.00 PLN.

Conflicts of Interest: The authors declare no conflict of interest.

\section{References}

1. Holzapfel, W.H. Appropriate starter culture technologies for small-scale fermentation in developing countries. Int. J. Food Microbiol. 2002, 3, 197-212. [CrossRef]

2. FAO/WHO. Probiotics in Food. Health and Nutritional Properties and Guidelines for Evaluation; FAO: Rome, Italy, 2002; pp. 1-59.

3. Di Cagno, R.; Coda, R.; De Angelis, M.; Gobbetti, M. Exploitation of vegetables and fruits through lactic acid fermentation. Food Microbiol. 2013, 33, 1-10. [CrossRef] [PubMed]

4. Sáez, G.D.; Hébert, E.M.; Saavedra, L.; Zárate, G. Molecular identification and technological characterization of lactic acid bacteria isolated from fermented kidney beans flours (Phaseolus vulgaris L. and P. coccineus) in northwestern. Food Res. Int. 2017, 102, 605-615. [CrossRef] [PubMed]

5. Jabłońska-Ryś, E.; Skrzypczak, K.; Sławińska, A.; Radzki, W.; Gustaw, W. Lactic acid fermentation of edible mushrooms: Tradition, technology, current state of research: A Review. Compr. Rev. Food Sci. Food Saf. 2019, 18, 265-669. [CrossRef]

6. Finimundy, T.C.; Gambato, G.; Fontana, R.; Camassola, M.; Salvador, M.; Moura, S.; Hess, J.; Henriques, J.A.P.; Dillon, A.J.P.; Roesch-Ely, M. Aqueous extracts of Lentinula edodes and Pleurotus sajor-caju exhibit high antioxidant capability and promising in vitro antitumor activity. Nutr. Res. 2013, 33, 76-84. [CrossRef]

7. Valverde, M.E.; Hernández-Pérez, T.; Paredes-López, O. Edible mushrooms: Improving human health and promoting quality life. Int. J. Microbiol. 2015, 2015, 376387. [CrossRef]

8. Manzi, P.; Aguzzi, A.; Pizzoferrato, L. Nutritional value of mushrooms widely consumed in Italy. Food Chem. 2001, 73, 321-325. [CrossRef]

9. Kim, Y.I.; Lee, Y.H.; Kim, K.H.; Oh, Y.K.; Moon, Y.H.; Kwak, W.S. Effects of supplementing microbially-fermented spent mushroom substrates on growth performance and carcass characteristics of Hanwoo steers (a field study). Asian Australas J. Anim. Sci. 2012, 25, 1575-1581. [CrossRef]

10. Baek, Y.C.; Kim, M.S.; Reddy, K.E.; Oh, Y.K.; Jung, Y.H.; Yeo, J.M.; Choi, H. Rumen fermentation and digestibility of spent mushroom (Pleurotus ostreatus) substrate inoculated with Lactobacillus brevis for Hanwoo steers. Rev. Colomb. Cienc. Pecu. 2017, 30, 267-277. [CrossRef]

11. Chen, Y.-S.; Yanagida, F.; Hsu, J.-S. Isolation and characterization of lactic acid bacteria from dochi (fermented black beans), a traditional fermented food in Taiwan. Lett. Appl. Microbiol. 2006, 43, 229-235. [CrossRef]

12. Waśko, A.; Szwajgier, D.; Polak-Berecka, M. The role of ferulic acid esterase in the growth of Lactobacillus helveticus in the presence of phenolic acids and their derivatives. Eur. Food Res. Technol. 2014, 238, $299-306$. [CrossRef]

13. Coeuret, V.; Dubernet, S.; Bernardeau, M.; Guegun, M.; Vernouxj, P. Isolation, characterization and identification of lactobacilli focusing mainly on cheeses and other dairy products. Le Lait 2003, 83, $269-306$. [CrossRef] 
14. Tajabadi, N.; Mardan, M.; Saari, N.; Mustafa, S.; Bahreini, R.; Manap, M.Y. Identification of Lactobacillus plantarum, Lactobacillus pentosus and Lactobacillus fermentum from honey stomach of honeybee. Braz. J. Microbiol. 2014, 44, 717-722. [CrossRef] [PubMed]

15. Gustaw, K.; Michalak, M.; Polak-Berecka, M.; Waśko, A. Isolation and characterization of a new fructophilic Lactobacillus plantarum FPL strain from honeydew. Ann. Microbiol. 2018, 68, 459-470. [CrossRef] [PubMed]

16. Sławińska, A.; Jabłońska-Ryś, E.; Stachniuk, A. High-performance liquid chromatography determination of Free sugars and mannitol in mushrooms using corona charged aerosol detection. Food Anal. Methods 2020, in press. [CrossRef]

17. Manini, F.; Casiraghi, M.C.; Poutanen, K.; Brasca, M.; Erba, D.; Plumed-Ferrer, C. Characterization of lactic acid bacteria isolated from wheat bran sourdough. LWT Food Sci. Technol. 2016, 66, 275-283. [CrossRef]

18. Ruas-Madiedo, P.; De Los Reyes-Gavilan, C.G. Invited review: Methods for the screening, isolation, and characterization of exopolysaccharides produced by lactic acid bacteria. J. Dairy Sci. 2005, 88, 843-856. [CrossRef]

19. Pérez-Sánchez, T.; Balcázar, J.L.; García, Y.; Halaihel, N.; Vendrell, D.; De Blas, I.; Merrifield, D.L.; Ruiz-Zarzuela, I. Identification and characterization of lactic acid bacteria isolated from rainbow trout, Oncorhynchus mykiss (Walbaum), with inhibitory activity against Lactococcus garvieae. J. Fish Dis. 2011, 34, 499-507. [CrossRef] [PubMed]

20. Gomes, B.C.; Rodrigues, M.R.; Winkelströter, L.K.; Nomizo, A.; de Martinis, E.C. In vitro evaluation of the probiotic potential of bacteriocin producer Lactobacillus sakei 1. J. Food Prot. 2012, 75, 83-89. [CrossRef]

21. Franz, C.M.; Specht, I.; Haberer, P.; Holzapfel, W.H. Bile salt hydrolase activity of enterococci isolated from food: Screening and quantitative determination. J. Food Prot. 2001, 64, 725-729. [CrossRef] [PubMed]

22. Torriani, S.; Felis, G.E.; Dellaglio, F. Differentiation of Lactobacillus plantarum, L. pentosus, and L. paraplantarum by recA Gene Sequence Analysis and Multiplex PCR Assay with recA Gene-Derived Primers. Appl. Environ. Microbiol. 2001, 67, 3450-3454. [CrossRef]

23. Available online: http://lactotax.embl.de/wuyts/lactotax/ (accessed on 20 September 2020).

24. Šušković, J.; Kos, B.; Beganović, J.; Leboš Pavunc, A.; Habjanić, K.; Matošić, S. Antimicrobial activity-The most important property of probiotic and starter lactic acid bacteria. Food Technol. Biotechnol. 2010, 48, 296-307.

25. Beganović, J.; Kos, B.; Leboš Pavunc, A.; Uroić, K.; Jokić, M.; Šušković, J. Traditionally produced sauerkraut as source of autochthonous functional starter cultures. Microbiol. Res. 2014, 169, 623-632. [CrossRef]

26. Klingberg, T.D.; Axelsson, L.; Naterstad, K.; Elsser, D.; Budde, B.B. Identification of potential probiotic starter cultures for Scandinavian-type fermented sausages. Int. Food Microbiol. 2005, 105, 419-431. [CrossRef]

27. Beganović, J.; Guillot, A.; van de Guchte, M.; Jouan, A.; Gitton, C.; Loux, V.; Roy, K.; Huet, S.; Monod, H.; Monnet, V. Characterization of the insoluble proteome of Lactococcus lactis by SDS-PAGE LC-MS/MS leads to the identification of new markers of adaptation of the bacteria to the mouse digestive tract. J. Proteome Res. 2010, 9, 677-688. [CrossRef]

28. Delgado, S.; Flórez, A.B.; Mayo, B. Antibiotic susceptibility of Lactobacillus and Bifidobacterium species from the human gastrointestinal tract. Curr. Microbiol. 2005, 50, 202-207. [CrossRef]

29. Breidt, F.J. A genomic study of Leuconostoc mesenteroides and the molecular ecology of sauerkraut fermentations. J. Food Sci. 2008, 69, FMS30-FMS33. [CrossRef]

30. Palys, T.; Nakamura, L.K.; Cohan, F.M. Discovery and classification of ecological diversity in the bacterial world: The role of DNA sequence data. Int. J. Syst. Bacteriol. 1997, 47, 1145-1156. [CrossRef]

31. Batista, N.N.; Ramos, C.L.; de Figueiredo Vilela, L.; Dias, D.R.; Schwan, R.F. Fermentation of yam (Dioscorea spp. L.) by indigenous phytase-producing lactic acid bacteria strains. Braz. J. Microbiol. 2019, 50, 507-514. [CrossRef]

32. Johanningsmeier, S.D.; McFeeters, R.F.; Fleming, H.P.; Thompson, R.L. Effects of Leuconostoc mesenteroides starter culture on fermentation of cabbage with reduced salt concentrations. J. Food Sci. 2007, 72, 166-172. [CrossRef]

33. Plengvidhya, V.; Breid, F.J.; Lu, Z.; Fleming, H.P. DNA fingerprinting of lactic acid bacteria in sauerkraut fermentation. Appl. Environ. Microbiol. 2007, 73, 7697-7702. [CrossRef]

34. Khaskheli, S.G.; Zheng, W.; Sheikh, S.A.; Khaskheli, A.A.; Liu, Y.; Wang, Y.F.; Huang, W. Effect of processing techniques on the quality and acceptability of Auricularia auricula mushroom pickle. J. Food Nutr. Res. 2015, 3, 46-51. [CrossRef] 
35. Buntin, N.; Chanthachum, S.; Hongpattarakere, T. Screening of lactic acid bacteria from gastrointestinal tracts of marine fish for their potential use as probiotics. SJST 2008, 30, 141-148.

36. Menconi, A.; Kallapura, G.; Latorre, J.D.; Morganm, J.; Pumford, N.R.; Hargis, B.M.; Tellez, G. Identification and characterization of lactic acid bacteria in a commercial probiotic culture. BMFH 2014, 33, 25-30. [CrossRef]

37. Wei, Z.; Huang, S.; Zhang, Y.; Li, H.; Zhou, S. Characterization of extracellular polymeric substances produced during nitrate removal by a thermophilic bacterium Chelatococcus daeguensis TAD1 in batch cultures. RSC Adv. 2017, 7, 44265-44271. [CrossRef]

38. Xia, P.F.; Li, Q.; Tan, L.R.; Sun, X.F.; Song, C.; Wang, S.G. Extracellular polymeric substances protect Escherichia coli from organic solvents. RSC Adv. 2016, 6, 59438-59444. [CrossRef]

39. Bartkiene, E.; Lele, V.; Starkute, V.; Zavistanaviciute, P.; Zokaityte, E.; Varinauskaite, I.; Pileckaite, G.; Paskeviciute, L.; Rutkauskaite, G.; Kanaporis, T.; et al. Plants and lactic acid bacteria combination for new antimicrobial and antioxidant properties product development in a sustainable manner. Foods 2020, 9, 433. [CrossRef] [PubMed]

40. Kosseva, M.R. Management and Processing of Food Wastes. In Comprehensive Biotechnology, 2nd ed.; Elsevier Inc.: Amsterdam, The Netherlands, 2011; Volume 6, pp. 558-593.

Publisher's Note: MDPI stays neutral with regard to jurisdictional claims in published maps and institutional affiliations.

(C) 2020 by the authors. Licensee MDPI, Basel, Switzerland. This article is an open access article distributed under the terms and conditions of the Creative Commons Attribution (CC BY) license (http://creativecommons.org/licenses/by/4.0/). 